\title{
Synthesis and characterization of 6FDA/3,5-diamino-2,4,6- trimethylbenzenesulfonic acid-derived polyimide for gas separation applications
}

Mahmoud A. Abdulhamid, Giuseppe Genduso, Xiaohua Ma, Ingo Pinnau*

Functional Polymer Membranes Group, Advanced Membranes and Porous Materials Center, Division of Physical Science and Engineering, King Abdullah University of Science and Technology (KAUST), Thuwal 23955, KSA.

*Corresponding author

E-mail: ingo.pinnau@kaust.edu.sa 


\section{ABSTRACT}

A sulfonic acid-functionalized trimethyl-substituted polyimide was synthesized by reacting $4,4^{\prime}-$ (hexafluoroisopropylidene)diphthalic anhydride (6FDA) and 3,5-diamino-2,4,6trimethylbenzenesulfonic acid (TrMSA). The properties of 6FDA-TrMSA were compared to the related 6FDA-derived polyimide analogues made from 2,4,6-trimethylbenzene-1,3-diamine (6FDA-TrMPD) and 3,5-diamino-2,4,6-trimethylbenzene benzoic acid (6FDA-TrMCA). Compared to 6FDA-TrMPD and 6FDA-TrMCA, sulfonic acid functionalization resulted in significantly lower surface area, reduced fractional free volume, and tighter chain $d$-spacing. Consequently, 6FDA-TrMSA displayed lower gas permeabilities with a commensurate increase in permeability-based gas-pair selectivities. The enhanced $\mathrm{CO}_{2} / \mathrm{CH}_{4}$ selectivity of $6 \mathrm{FDA}-\mathrm{TrMSA}$ was caused exclusively by higher diffusion selectivity, which was promoted by strong hydrogen bonding induced by the $-\mathrm{SO}_{3} \mathrm{H}$ functionalization. Permeation experiments of 6FDA-TrMSA with a 1:1 $\mathrm{CO}_{2}-\mathrm{CH}_{4}$ mixture revealed the occurrence of competitive sorption effects (depressing $\mathrm{CO}_{2}$ gas permeability) and $\mathrm{CO}_{2}$-induced polymer matrix plasticization, which reduced the polymer selectivity by enhancing $\mathrm{CH}_{4}$ permeability. At $\sim 20$ atm total pressure, 6FDA-TrMSA showed a $\mathrm{CO}_{2}$ permeability of $\sim 15$ Barrer and an equimolar $\mathrm{CO}_{2} / \mathrm{CH}_{4}$ mixed-gas selectivity of 55 , which are $\sim 2$-fold higher performance values than those of the state-of-the-art polymer used for industrial scale natural gas sweetening, i.e., cellulose triacetate. 


\section{Introduction}

Polyimides are attractive high-performance materials applied widely in industrial applications because of their variable processability, high thermal, mechanical and chemical stability [1]. Structure-property relationships of polyimides with respect to their gas transport properties have been extensively investigated. By proper choice of the polymer backbone substituents, the gas separation performance may be optimized by either disrupting the polymer chain packing to enhance permeability or promoting interchain interactions to boost permeability selectivity [2-13].

Introduction of methyl groups to phenylenediamine-derived polyimides has often been used as a simple and effective way to enhance the gas permeability by restricting the rotational mobility of the imide linkages and providing spacer groups for inefficient interchain packing [14]. Specifically, polyimides based on 4,4'-(hexafluoroisopropylidene)diphthalic anhydride (6FDA) and 2,4,6-trimethyl-1,3-phenylenediamine (TrMPD) or 2,3,5,6-tetramethyl-1,4-phenylenediamine (TeMPD) showed enhanced gas permeabilities compared to their unsubstituted 1,3-phenylene diamine (MPD) and 1,4-phenylenediamine (PPD) analogues; however, the boost in permeability also resulted in a significant commensurate drop in selectivity [15-17]. Because of its high permeability, TrMPD has been applied as a monomer for fine-tuning an appropriate balance between gas permeability and selectivity by designing a wide variety of co-polyimides [15-17].

Previous studies demonstrated that integrating polar groups in the polyimide backbone, e.g., hydroxyl $(-\mathrm{OH})$ [10,11,18-27] and carboxyl $(-\mathrm{COOH})$ [28-34] groups, can enhance their performance, specifically for $\mathrm{CO}_{2} / \mathrm{CH}_{4}$ separation [10,18,21-34]. The hydroxyl and carboxyl groups promote interchain hydrogen bonding and trigger charge transfer complex (CTCs) interactions, which typically lead to polyimides with tighter chain packing and enhanced gas-pair selectivity coupled with some loss in permeability $[10,24,27]$ 
Alternatively, sulfonic acid $\left(-\mathrm{SO}_{3} \mathrm{H}\right)$ groups can be used to functionalize polyimides, which have been investigated extensively as ion-conducting membrane materials [35-40]. Furthermore, several studies reported the gas transport properties of sulfonated polyimides [41-48]. Tanaka et al. investigated polyimides made from 1,4,5,8-naphthalene tetracarboxylic dianhydride (NTDA) and 2,2- bis[4-(4-aminophenoxy)phenyl] hexafluoropropane (BAPHF) and the sulfonated analogues bearing sulfonic acid $\left(-\mathrm{SO}_{3} \mathrm{H}\right)$ or triethylamine sulfonate $\left(-\mathrm{SO}_{3} \mathrm{NHEt}_{3}\right)$ groups [46]. When tested under pure-gas conditions at $35^{\circ} \mathrm{C}$ and $1 \mathrm{~atm}$, the sulfonic-acid-containing NTDABAPHFDA-H polyimide exhibited higher $\mathrm{CO}_{2} / \mathrm{CH}_{4}$ permeability selectivity than the triethylamine-sulfonate-based NTDA-BAPHFDS-A polyimide (81 vs. 35). At the same time, both polymers displayed about the same $\mathrm{CO}_{2}$ permeability of 13-14 Barrer [46]. More recently, a series of sulfonated polyimides was reported by Zhang et al. [48]. TEA-tSPI (see structure in Scheme 1), prepared from 6FDA and the $\mathrm{SO}_{3} \mathrm{NHEt}_{3}$ salt of 3,5-diamino-2,4,6-trimethylbenzenesulfonic acid (TrMSA), displayed a $\mathrm{CO}_{2}$ permeability of 52 Barrer with pure-gas $\mathrm{CO}_{2} / \mathrm{CH}_{4}$ selectivity of 33 (at $1 \mathrm{~atm}$ and $35^{\circ} \mathrm{C}$ ) [48].

Here, we report the sulfonated polyimide prepared by the polycondensation reaction of TrMSA with 6FDA in $m$-cresol (Scheme 1). We present the structural and physical polymer properties, including gas sorption, diffusion, and permeability of 6FDA-TrMSA. To elucidate the effects of specific functionalization groups on gas transport properties, we compared 6FDA-TrMSA with previously reported triethylamine-sulfonated- [48], carboxylated- [33] and non-functionalized 6FDA-TrMPD [33] analogues - i.e., TEA-tSPI, 6FDA-TrMCA and 6FDA-TrMPD polyimide. We also performed $\mathrm{CO}_{2} / \mathrm{CH}_{4}$ gas mixture permeation studies to investigate the potential of $6 \mathrm{FDA}$ TrMSA for natural gas or biogas applications. 


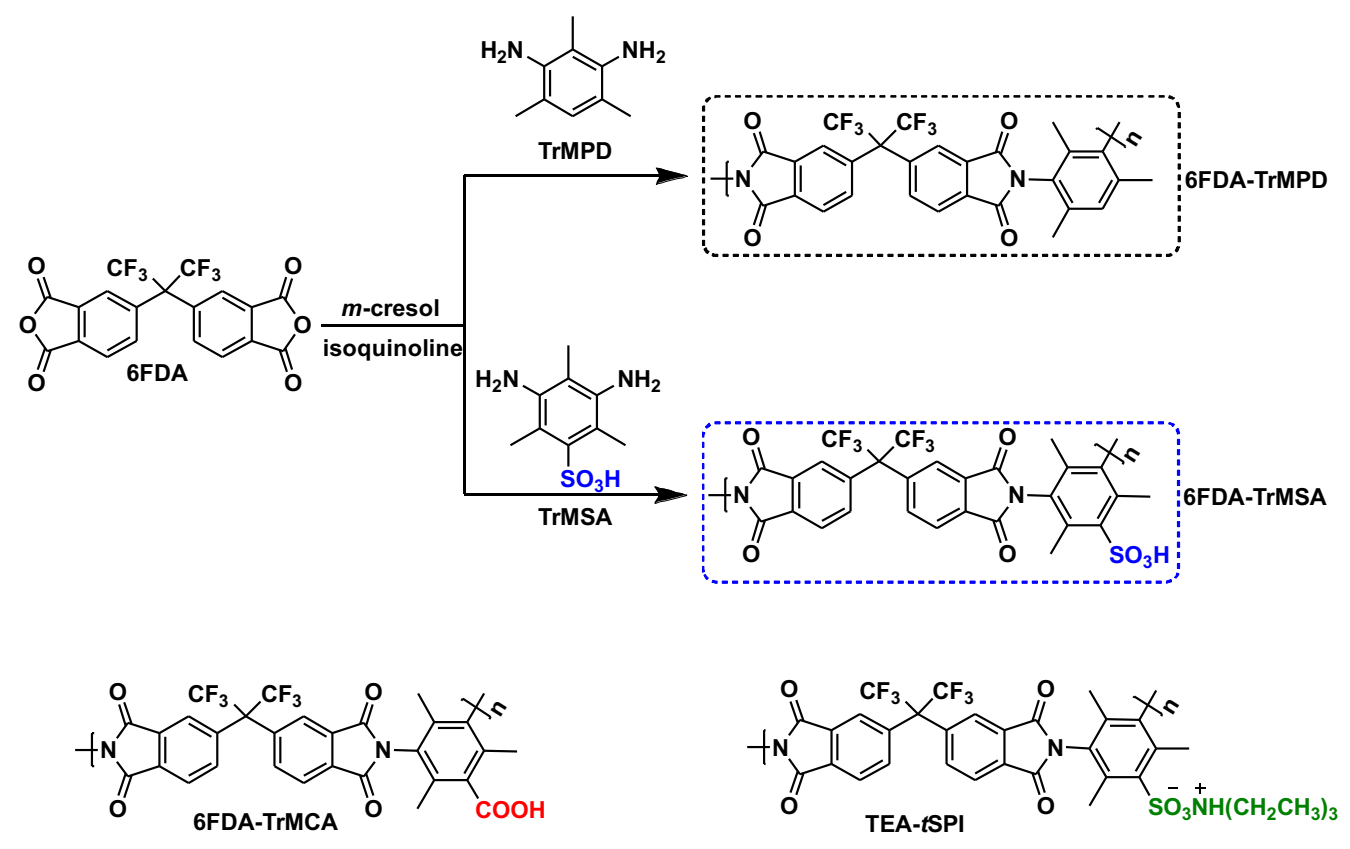

Scheme 1. Synthetic scheme for synthesis of 6FDA-TrMSA. Structures of previously reported 6FDA-TrMPD, 6FDA-TrMCA and TEA-tSPI polyimides are included for comparison $[33,48]$.

\section{Experimental}

\subsection{Materials and characterizations}

6FDA (99\%) and TrMSA (97\%) were obtained from Tokyo Chemical Industry Co., Ltd. (JP) (TCI). Solvents were purchased from Sigma-Aldrich and used without further purification. All polymer characterizations were performed as described in our previous work [25] and are described in the Supporting Information of this work.

\subsection{Polymer synthesis}

6FDA-TrMSA was synthesized by reacting 6FDA (0.58 g, $1.3 \mathrm{mmol})$ and TrMSA (0.3 g, 1.3 mmol) in $m$-cresol $(4 \mathrm{ml})$ in the presence of isoquinoline $(0.1 \mathrm{ml})$, as shown in Scheme 1. The 
solution was stirred for $20 \mathrm{~min}$ at room temperature under a continuous flow of nitrogen. The temperature was then gradually increased to $200{ }^{\circ} \mathrm{C}$ while stirring continued for $6 \mathrm{~h}$. The water resulting from the reaction was continuously removed with a nitrogen stream. The highly viscous solution was cooled and precipitated in methanol $(300 \mathrm{ml})$ at room temperature. The obtained light brown polymer was re-precipitated two times from dimethylformamide (DMF) solution into methanol and then dried under vacuum for $24 \mathrm{~h}$ at $200{ }^{\circ} \mathrm{C}$; $\left(92 \%\right.$ yield). ${ }^{1} \mathrm{H}$ NMR (400 MHz, DMSO- $\left.d_{6}\right): \delta 1.93$ (br s, 3H), 2.17 (br s, 6H), 7.95 (br m, 4H), 8.19 (br s, 2H). FT-IR $\left(v, \mathrm{~cm}^{-1}\right)$ : 3100-3600 (br, str O-H), 1791 (C=O asym), 1718 (C=O sym, str), 1351 (C-N, str), 1191 and 1047 $(\mathrm{O}=\mathrm{S}=\mathrm{O}, \mathrm{str}), 712$ (imide ring deformation); $\mathrm{M}_{\mathrm{n}}=106,000 \mathrm{~g} \mathrm{~mol}^{-1} ; \mathrm{PDI}=1.28$; TGA analysis: $\mathrm{T}_{\mathrm{d}, 5 \%}=316{ }^{\circ} \mathrm{C} ; \mathrm{S}_{\mathrm{BET}}=40 \mathrm{~m}^{2} \mathrm{~g}^{-1} ; \rho=1.41 \mathrm{~g} \mathrm{~cm}^{-3}$.

\subsection{Polymer film preparation}

A $3 \mathrm{wt} / \mathrm{vol} \%$ 6FDA-TrMSA solution in DMF was filtered through a $0.45 \mu \mathrm{m}$ PTFE filter in a glass Petri dish. The polymer solution was then heated at $80^{\circ} \mathrm{C}$ for $24 \mathrm{~h}$ under continuous nitrogen flow to evaporate DMF. Finally, the pre-dried film was further heated at $200^{\circ} \mathrm{C}$ for $24 \mathrm{~h}$ under vacuum. Films with a thickness of $\sim 45 \mu \mathrm{m}$ were used for the gas permeation measurements.

\subsection{Gas sorption and permeation experiments}

Gravimetric gas sorption experiments were performed as previously reported [33]. Pure-gas permeation experiments were performed at $2 \mathrm{~atm}$ and $35^{\circ} \mathrm{C}$ in the following order: $\mathrm{H}_{2}, \mathrm{~N}_{2}, \mathrm{O}_{2}$, $\mathrm{CH}_{4}$, and $\mathrm{CO}_{2}$; the details of the procedure are described in the Supporting Information. Furthermore, pure $\mathrm{CO}_{2}$ and $\mathrm{CH}_{4}$ permeation data were generated over a pressure range of 2-18 
atm. Permeation experiments were also conducted with a 1:1 molar $\mathrm{CO}_{2} / \mathrm{CH}_{4}$ mixture with a total maximum pressure of up to $32 \mathrm{~atm}$, as previously described [25].

\subsection{Molecular Dynamics Simulation}

Molecular dynamics simulations to estimate FFV and hydrogen bonding sites were performed by the same methodology as reported in previous work [33]. The occurrence of hydrogen bonding between the simulated polymer chains was elucidated by imposing a maximum bond distance of $4 \AA$ between the donor and acceptor sites. The modeling results of 6FDA-TrMSA are displayed together with those of 6FDA-TrMPD and 6FDA-TrMCA polyimides in Fig. S1.

\section{Results and discussion}

\subsection{Synthesis and characterization of the polyimides}

The synthesis of the 6FDA-TrMSA polyimide was carried out using a conventional hightemperature polycondensation reaction of equimolar amounts of 6FDA and TrMSA in $m$-cresol at $200{ }^{\circ} \mathrm{C}$. The ${ }^{1} \mathrm{H}$ NMR spectrum of 6 FDA-TrMSA matched the expected chemical structure and is compared to that of 6FDA-TrMPD in Fig. 1. No signals were detected above $10 \mathrm{ppm}$, indicating full conversion of poly(amic acid) to polyimide.

The characteristic peaks of the imide group were detected at 1791 (asymmetric $\mathrm{C}=\mathrm{O}$ stretching) and $1718 \mathrm{~cm}^{-1}$ (symmetric $\mathrm{C}=\mathrm{O}$ stretching) for 6FDA-TrMSA. The hydroxyl stretching frequency of the $-\mathrm{SO}_{3} \mathrm{H}$ group was obtained as a wide band between 3100 and $3600 \mathrm{~cm}^{-1}$, and the $\mathrm{S}-\mathrm{O}$ and $\mathrm{S}=\mathrm{O}$ stretching frequency was found at 1047 and $1191 \mathrm{~cm}^{-1}$, respectively (Fig. 2). 


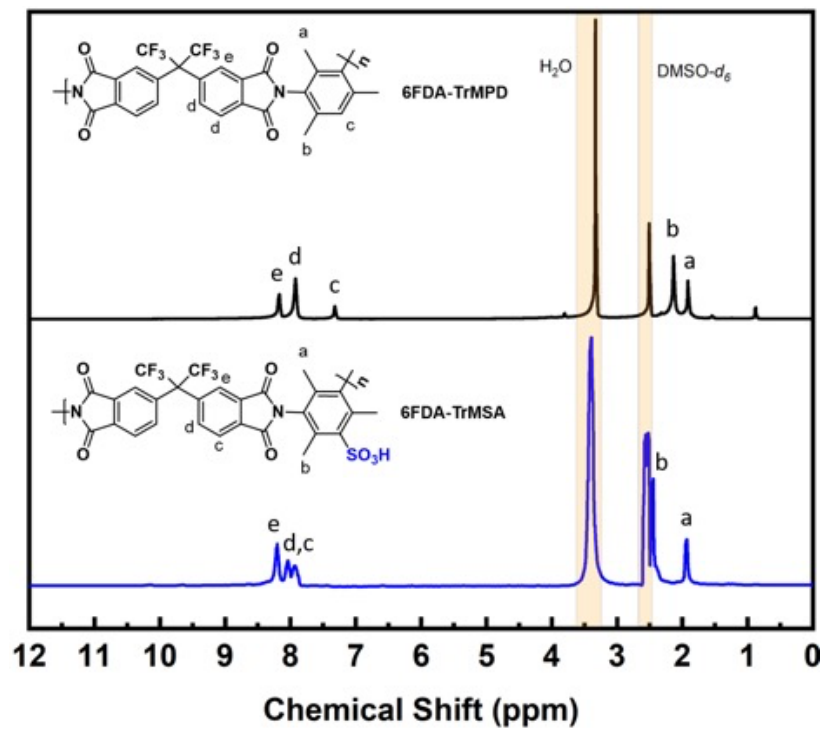

Fig. 1. ${ }^{1} \mathrm{H}$ NMR spectra of 6FDA-TrMSA and 6FDA-TrMPD [33] in deuterated dimethylsulfoxide $\left(\mathrm{DMSO}-\mathrm{d}_{6}\right)$.
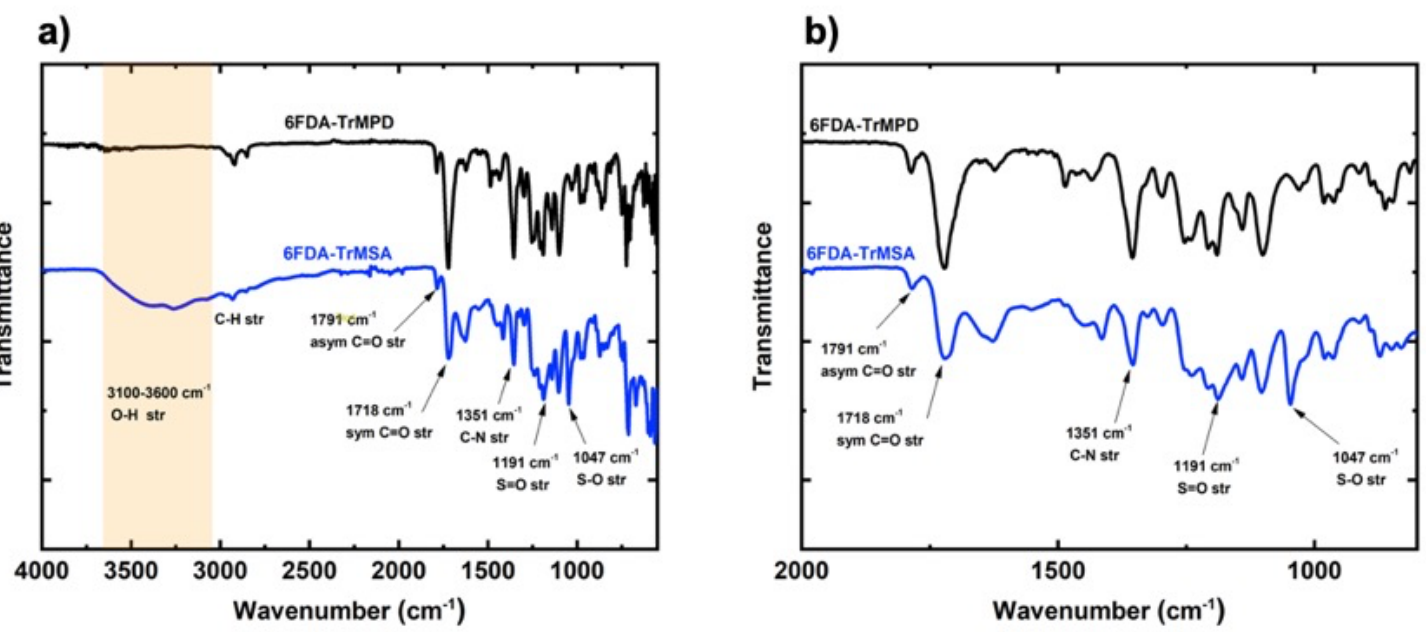

Fig. 2. FT-IR spectra of 6FDA-TrMSA and 6FDA-TrMPD [33] polyimides. a) identification of $\mathrm{O}-\mathrm{H}$ stretching and imide formation $(\mathrm{C}=\mathrm{O}$ stretching, $\mathrm{C}-\mathrm{N}$ stretching $)$; b) identification of $-\mathrm{SO}_{3} \mathrm{H}$ group at 1047 and $1191 \mathrm{~cm}^{-1}$.

Like the previously reported carboxylated 6FDA-TrMCA [33], the sulfonated 6FDA-TrMSA polyimide exhibited excellent solubility at $23{ }^{\circ} \mathrm{C}$ in high boiling point polar solvents but was 
insoluble in chlorinated solvents, i.e., dichloromethane (DCM) and chloroform $\left(\mathrm{CHCl}_{3}\right)(\mathbf{T a b l e}$ 1).

\section{Table 1}

Solubility of 6FDA-TrMSA in common organic solvents.

\begin{tabular}{ccccccccc}
\hline Polymer & DCM & $\mathrm{CH}_{3} \mathrm{Cl}$ & THF & NMP & DMF & DMAc & DMSO & $m$-cresol \\
\hline 6FDA-TrMPD [33] & ++ & ++ & ++ & ++ & ++ & ++ & ++ & ++ \\
6FDA-TrMCA [33] & -- & -- & ++ & ++ & ++ & ++ & ++ & ++ \\
$\begin{array}{c}\text { 6FDA-TrMSA } \\
\text { [this study] }\end{array}$ & -- & -- & -+ & ++ & ++ & ++ & ++ & ++ \\
\hline
\end{tabular}

--: insoluble, -+: soluble with heating, ++ : soluble at room temperature.

6FDA-TrMSA displayed high $\mathrm{M}_{\mathrm{n}}$ of $106,000 \mathrm{~g} \mathrm{~mol}^{-1}$ and PDI of 1.28. Thermal gravimetric analysis of 6FDA-TrMSA, shown in Fig. 3, indicated decomposition of 6FDA-TrMSA in two steps: (i) the first started at $\sim 270{ }^{\circ} \mathrm{C}$ and was primarily due to the thermal removal of the functional $-\mathrm{SO}_{3} \mathrm{H}$ group; (ii) the second stage starting at $\sim 400{ }^{\circ} \mathrm{C}$ marked the main chain degradation. A similar behavior was observed for the carboxyl-functionalized version of the 6FDA-TrMPD (i.e., 6FDA-TrMCA), where degradation of the $-\mathrm{COOH}$ group occurred at $\sim 350{ }^{\circ} \mathrm{C}$ [33]. 6FDATrMPD, 6FDA-TrMCA and 6FDA-TrMSA displayed decomposition temperatures at 5\% weight loss $\left(\mathrm{T}_{\mathrm{d}}, 5 \%\right)$ of 502,404 and $316^{\circ} \mathrm{C}$, respectively, under nitrogen atmosphere (Table 2). 

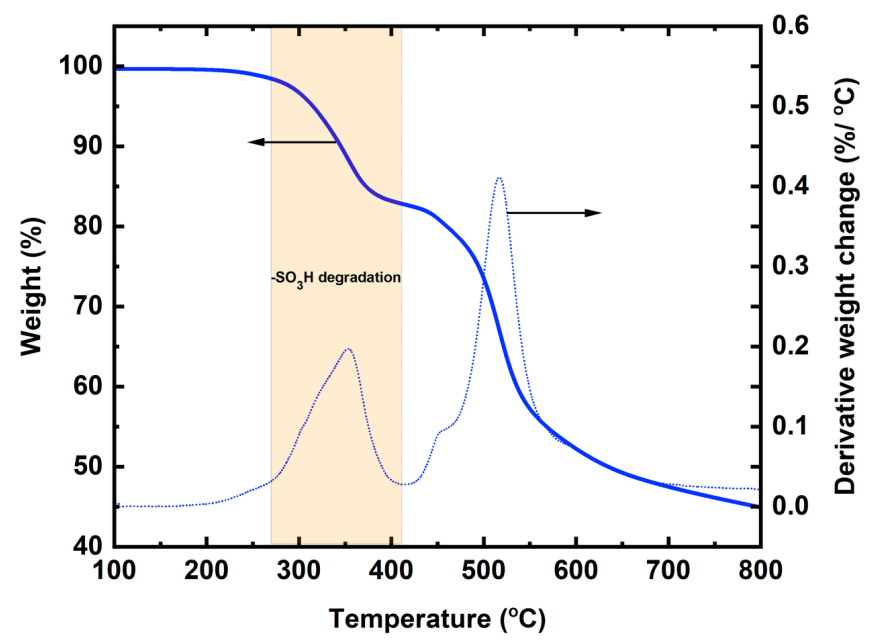

Fig. 3. Thermal gravimetric analysis (TGA) of 6FDA-TrMSA polyimide.

\section{Table 2}

Physical properties of 6FDA-TrMSA. Data for 6FDA-TrMPD and 6FDA-TrMCA are included for comparison.

\begin{tabular}{lccccc}
\hline \multicolumn{1}{c}{ Polymer } & $\mathrm{T}_{\mathrm{d}, 5 \%}\left({ }^{\circ} \mathrm{C}\right)^{a}$ & ${\text { Carbon }(\%)^{b}}$ & $\mathrm{~S}_{\mathrm{BET}}\left(\mathrm{m}^{2} \mathrm{~g}^{-1}\right)^{c}$ & $\rho\left(\mathrm{g} \mathrm{cm}^{-3}\right)^{d}$ & ${\mathrm{FFV}(-)^{e}}^{e}$ \\
\hline 6FDA-TrMPD [33] & 502 & $66 \%$ & 450 & 1.24 & 0.25 \\
6FDA-TrMCA [33] & 404 & $50 \%$ & 260 & 1.31 & 0.21 \\
6FDA-TrMSA [this study] & 316 & $45 \%$ & 40 & 1.41 & 0.14 \\
\hline
\end{tabular}

${ }^{a}$ Measured by TGA at $5 \%$ weight loss.

${ }^{b}$ Obtained from TGA representing the residual carbon at $800{ }^{\circ} \mathrm{C}$.

${ }^{c}$ BET surface area determined from $\mathrm{N}_{2}$ adsorption isotherms at $-196{ }^{\circ} \mathrm{C}$.

${ }^{d}$ Geometric density.

${ }^{e}$ Estimated FFV from MD simulations.

\subsection{Microstructure of the $-\mathrm{SO}_{3} \mathrm{H}$-functionalized polyimide}

In this section, we discuss the difference between introducing $-\mathrm{SO}_{3} \mathrm{H}$ and $-\mathrm{COOH}$ [33] functionalities to the polymer backbone. To this aim, it is helpful to identify the potential types of hydrogen bonding sites in the 6FDA-TrMSA polymer matrix, as derived by molecular dynamic simulations (Fig. 4). 
a)
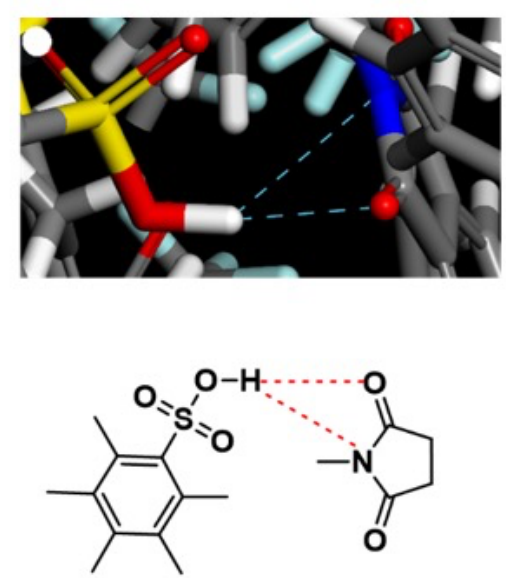

b)
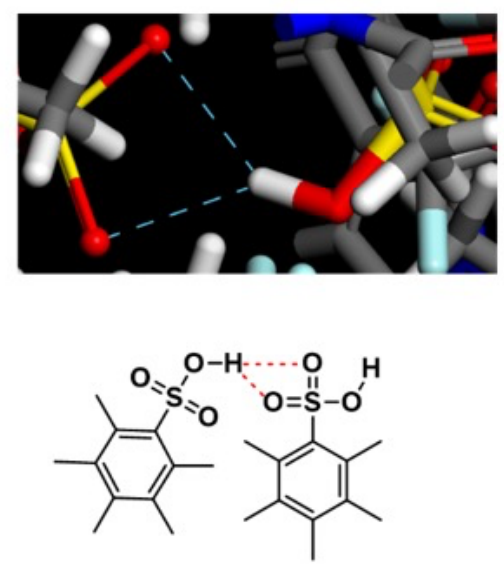

c)
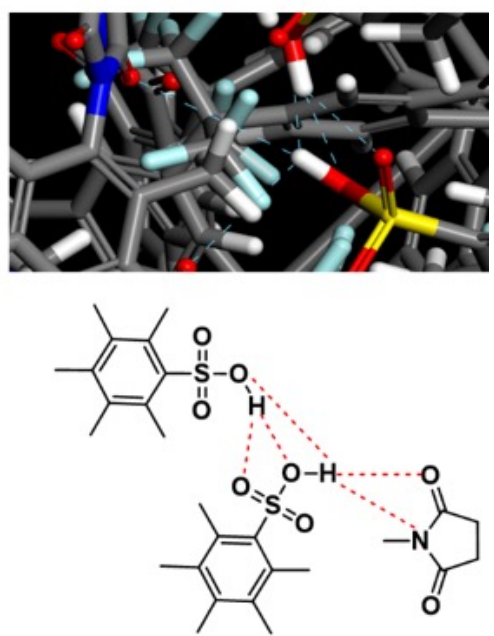

Fig. 4. Possible hydrogen bonding sites in 6FDA-TrMSA identified by MD simulations.

The sulfonic acid group $\left(-\mathrm{SO}_{3} \mathrm{H}\right)$ can create hydrogen bonds with both the carbonyl and imide groups (Fig. 4a) of neighboring polymer chains. Moreover, the $-\mathrm{OH}$ donor sites are likely to create hydrogen bonds with the $-\mathrm{SO}_{2}$ of the adjacent chains, as shown in Fig. $\mathbf{4 b}$ and $\mathbf{4 c}$. Hence, the sulfonic acid functionalization acts similarly to the carboxyl group in 6FDA-TrMCA, which also provides hydrogen bonding donor and acceptor sites [33]. However, the interchain interactions promoted by the sulfonic acid group are much stronger than those obtainable by the carboxylic acid functionality, as indicated by comparing the pKa (i.e., the negative logarithm of the acid dissociation constant) of two acids bearing the sulfonic and carboxyl functionality, i.e., benzenesulfonic acid $(\mathrm{pKa}=-2.8)$ is a much stronger acid than benzoic acid ( $\mathrm{pKa}$ of 4.2). Thus, the $-\mathrm{SO}_{3} \mathrm{H}$ group will induce stronger hydrogen bonding, which results in tighter interchain packing in 6FDA-TrMSA than the - $\mathrm{COOH}$-functionalized 6FDA-TrMCA and significantly more than the non-functionalized 6FDA-TrMPDA analogue. To support this hypothesis, it is informative to compare the BET surface area of 6FDA-TrMPD with the two acid-functionalized 6FDA-TrMPD-based polyimides. The intrinsically microporous, non-functionalized 6FDA- 
TrMPD displayed a high BET surface area of $450 \mathrm{~m}^{2} \mathrm{~g}^{-1}$ [33], while after $-\mathrm{COOH}$ functionalization, the BET surface area decreased to $260 \mathrm{~m}^{2} \mathrm{~g}^{-1}$ for 6FDA-TrMCA [33]. Introducing $-\mathrm{SO}_{3} \mathrm{H}$ to the polymer backbone led to an even much larger reduction in $\mathrm{BET}$ surface area to only $40 \mathrm{~m}^{2} \mathrm{~g}^{-1}$ for 6FDA-TrMSA (Fig. S2), a value similar to other low-free-volume polyimides [25]. This result is also supported by the qualitative trends in other physical properties, in which 6FDA-TrMSA showed higher density and lower FFV values relative to 6FDA-TrMCA and 6FDA-TrMPD (Table 2).

To analyze the pore size distribution of 6FDA-TrMSA, NLDFT modeling of the $\mathrm{CO}_{2}$ adsorption isotherm at $273 \mathrm{~K}$ permitted us to identify two groups of ultramicropores: the first with an average pore width of $\sim 3.6 \AA$ and the second in the range 5-7.5 $\AA$ (Fig. S3a). In agreement with this observation, the deconvolution of the X-ray diffraction spectrum of 6FDA-TrMSA displayed two groups of amorphous peaks, the first with an average $d$-spacing of 5.1 and $6.9 \AA$ (Fig. 5, Fig. S4) and the second consisting of two less pronounced peaks at 3.1 and $3.7 \AA$. Hence, the interchain hydrogen bonding associated with the $-\mathrm{SO}_{3} \mathrm{H}$ functionality tightens the polymer structure by creating diffusion domains with pore width of $\sim 3.5 \AA$, which are tailored for diffusion-selective $\mathrm{CO}_{2}$ permeation. Fig. 5 displays how the X-ray diffraction spectrum of 6FDATrMSA shifted toward a tighter chain structure than for the unfunctionalized and $-\mathrm{COOH}-$ functionalized polyimides. Indeed, 6FDA-TrMSA revealed the most pronounced size sieving character in this polyimide series, as discussed in Section 3.4. 


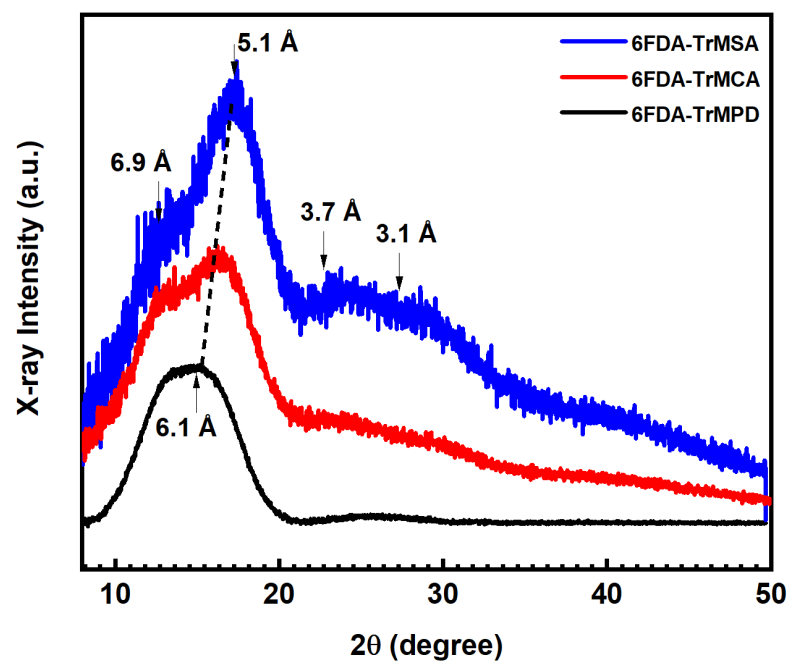

Fig. 5. Wide-angle X-ray diffraction (WAXD) spectrum of 6FDA-TrMSA polyimide and comparison with that of the unfunctionalized (6FDA-TrMPD) and-COOH-functionalized versions (6FDA-TrMCA) [33].

\subsection{Fluorescence spectra}

In polyimides, the delocalization of the $\pi$-electrons induces charge-transfer complexes (CTCs) of electron withdrawing groups of the dianhydride and electron-donating groups of the diamine $[24,25,49]$. Integrating polar functional groups (i.e. $\mathrm{OH}$, and $\mathrm{COOH}$ ) to the polymer chains reduces the FFV of an amorphous polymer by promoting interchain interactions and, thus, CTC formation. Hence, the CTC interactions tightens the polymer chain structure. In general, the fluorescence emission intensity is proportional to the strength of CTCs within a polymer matrix. Previously, we showed how the inclusion of the carboxyl functionality into the 6FDA-TrMPD polyimide increased the interchain interactions and promoted CTCs formation [33]. These CTCs interactions were even further enhanced by introducing the $-\mathrm{SO}_{3} \mathrm{H}$ functionality, as the fluorescence emission intensity of the 6FDA-TrMSA was substantially higher than that observed for the carboxylfunctionalized 6FDA-TrMCA (Fig. 6). The higher fluorescence intensity is macroscopically visible by the coloration of the polyimide films, i.e., 6FDA-TrMSA and 6FDA-TrMCA displayed 
dark brown and light-yellow colors, respectively, whereas 6FDA-TrMPD was essentially colorless.
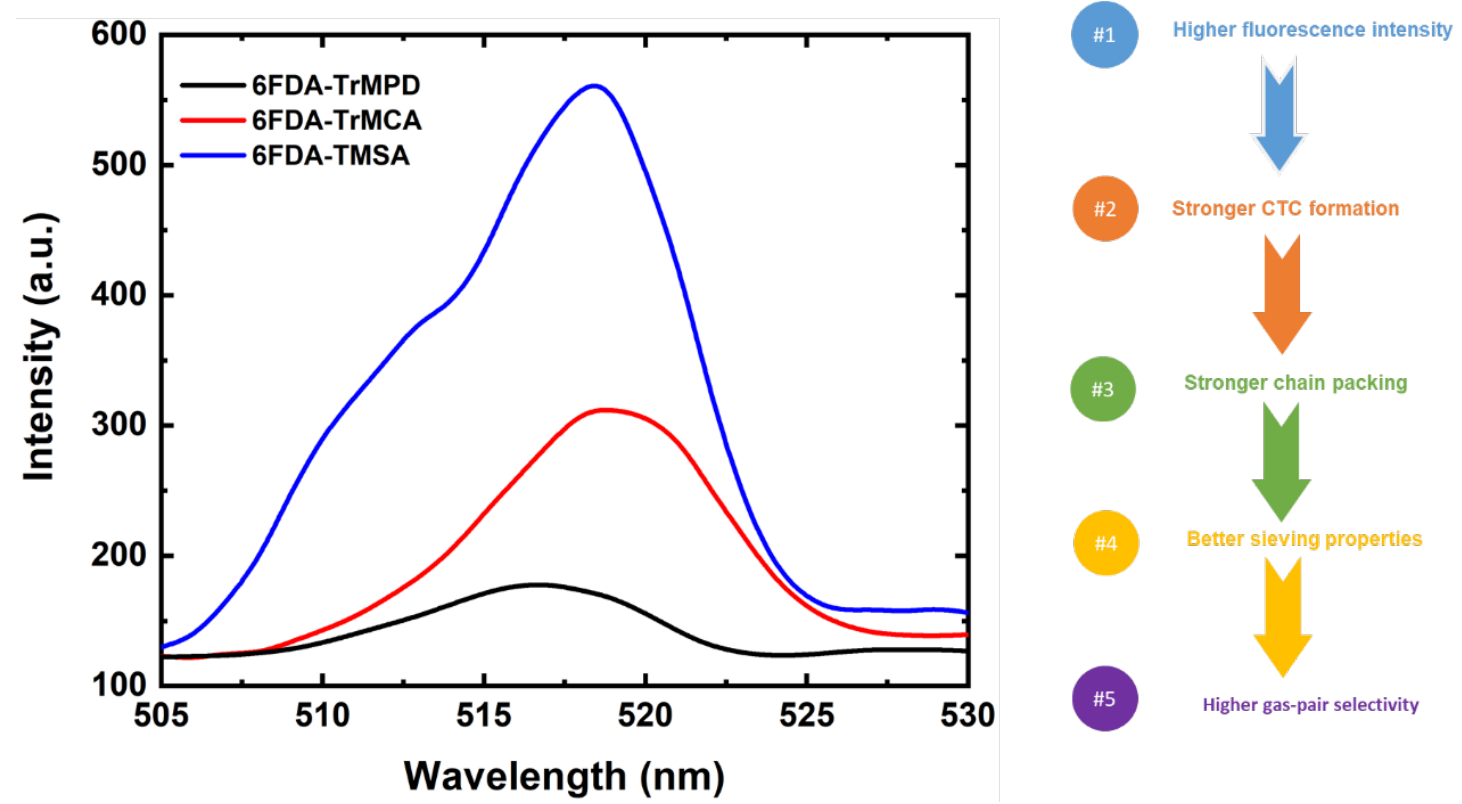

Fig. 6. Fluorescence emission spectra of 6FDA-TrMSA (excitation at $380 \mathrm{~nm}$ ) in comparison with related polyimides (film thickness $12-15 \mu \mathrm{m}$ ) [33] and typical trends of CTC formation on chain packing and gas permeation properties.

\subsection{Pure-gas transport properties}

The pure-gas permeation properties of 6FDA-TrMSA polyimide are summarized in Table 3; data for 6FDA-TrMPD, 6FDA-TrMCA [33], TEA-tSPI [48], and three reference polymers used for commercial gas separation membranes, i.e., cellulose triacetate (CTA) [50], polysulfone [51] and polyimide (Matrimid) [51], are included for comparison.

Compared to the non-functionalized 6FDA-TrMPD, the 6FDA-TrMSA polyimide was strongly size-selective due to tight chain packing resulting from the vast hydrogen bonding and CTCs interactions triggered by the $-\mathrm{SO}_{3} \mathrm{H}$ functionalization. However, the tightening of the polymer structure was also coupled with a decrease in gas permeability (Table 3). For example, 
the introduction of the $-\mathrm{SO}_{3} \mathrm{H}$ functionality to $6 \mathrm{FDA}-\mathrm{TrMPD}$ led to a notable 3 -fold enhancement in $\mathrm{CO}_{2} / \mathrm{CH}_{4}$ selectivity from 22 to 61 but was penalized by a $\sim 25$-fold decrease in $\mathrm{CO}_{2}$ permeability, i.e., from 498 to 19 Barrer (Table 3). Moreover, the presence of $-\mathrm{SO}_{3} \mathrm{H}$ in 6FDATrMSA boosted the $\mathrm{H}_{2} / \mathrm{CH}_{4}$ selectivity of 6FDA-TrMPD from 18 to 180 with $\sim$ 7-fold reduction in $\mathrm{H}_{2}$ permeability from 407 to 56 Barrer. Interestingly, 6FDA-m-phenylenediamine (6FDAMPD), a related non-functionalized low-free-volume polyimide, without both $-\mathrm{SO}_{3} \mathrm{H}$ functionality and trimethyl-substitution, exhibited similar pure-gas permeabilities and selectivities compared to 6FDA-TrMSA (Table 3). Importantly, the 6FDA-TrMPD polyimide displayed higher $\mathrm{H}_{2}$ and $\mathrm{CO}_{2}$ permeability as well as enhanced $\mathrm{H}_{2} / \mathrm{N}_{2}, \mathrm{H}_{2} / \mathrm{CH}_{4}$ and $\mathrm{CO}_{2} / \mathrm{CH}_{4}$ selectivity than commonly used commercial membrane materials, such as cellulose triacetate, polysulfone and polyimide (Matrimid).

Table 3

Pure-gas permeability and selectivity of 6FDA-TrMSA. Properties of related polyimides and commercial membrane polymers are provided for comparison.

\begin{tabular}{lccccccccc}
\hline \multirow{2}{*}{ Polymer } & \multicolumn{4}{c}{${\text { Permeability }(\mathrm{Barrer})^{a}}^{a}$} & \multicolumn{4}{c}{${\text { Ideal selectivity }\left(\mathrm{\alpha}_{\mathrm{X} / \mathrm{Y}}\right)}$} \\
\cline { 2 - 10 } & $\mathrm{H}_{2}$ & $\mathrm{~N}_{2}$ & $\mathrm{O}_{2}$ & $\mathrm{CH}_{4}$ & $\mathrm{CO}_{2}$ & $\mathrm{H}_{2} / \mathrm{N}_{2}$ & $\mathrm{H}_{2} / \mathrm{CH}_{4}$ & $\mathrm{O}_{2} / \mathrm{N}_{2}$ & $\mathrm{CO}_{2} / \mathrm{CH}_{4}$ \\
\hline 6FDA-MPD $^{b}[25]$ & 46 & 0.62 & 3.6 & 0.20 & 14 & 74 & 230 & 5.8 & 70 \\
\hline 6FDA-TrMPD $^{b}[33]$ & 407 & 25.3 & 91.4 & 23.0 & 498 & 16 & 18 & 3.6 & 22 \\
\hline 6FDA-TrMCA $^{b}[33]$ & 193 & 5.52 & 26.4 & 3.2 & 144 & 35 & 61 & 4.8 & 45 \\
\hline 6FDA-TrMSA $^{b}[$ This work] & 56 & 0.6 & 3.8 & 0.31 & 19 & 93 & 180 & 6.3 & 61 \\
\hline 6FDA-tSPI (TEAsalt) $^{c}[48]$ & 58 & 1.87 & 8.19 & 1.58 & 52.2 & 31 & 37 & 4.4 & 33 \\
\hline Cellulose triacetate [50] & 15.5 & 0.23 & 1.46 & 0.20 & 6.6 & 67 & 78 & 6.3 & 33 \\
\hline Polysulfone [51] & 14.0 & 0.25 & 1.40 & 0.25 & 5.6 & 56 & 56 & 5.6 & 22 \\
\hline Polyimide (Matrimid) [51] & 18.0 & 0.32 & 2.10 & 0.28 & 10.0 & 56 & 64 & 6.6 & 36 \\
\hline
\end{tabular}

\footnotetext{
${ }^{\alpha} 1$ barrer $=10^{-10} \mathrm{~cm}^{3}(\mathrm{STP}) \mathrm{cm} \mathrm{cm}^{-2} \mathrm{~s}^{-1} \mathrm{cmHg}^{-1}$.

${ }^{b}$ Treated at $200{ }^{\circ} \mathrm{C}$ for $24 \mathrm{~h}$ under vacuum and tested at 2 atm and $35^{\circ} \mathrm{C}$.

${ }^{c}$ Treated at $150{ }^{\circ} \mathrm{C}$ for $8 \mathrm{~h}$ under vacuum and tested at $1 \mathrm{~atm}$ and $35^{\circ} \mathrm{C}$ [48].
} 
To further investigate the effect of the $-\mathrm{SO}_{3} \mathrm{H}$ group on the pure-gas transport performance of 6FDA-TrMSA, we measured the gas uptake of $\mathrm{CO}_{2}$ and $\mathrm{CH}_{4}$ by gravimetric sorption at $35^{\circ} \mathrm{C}$ and up to $\sim 15 \mathrm{~atm}$ (Fig. S4). We then deduced the gas diffusion coefficients from the relationship $D$ $=P / S($ Table 4$)$.

Introduction of the highly polar $-\mathrm{SO}_{3} \mathrm{H}$ group had a relatively small effect on the $\mathrm{CO}_{2}$ and $\mathrm{CH}_{4}$ sorption coefficients compared to the non-functionalized 6FDA-TrMPD polyimide; moreover, the $\mathrm{CO}_{2} / \mathrm{CH}_{4}$ solubility selectivity values varied only over a narrow range from 3.6 to 4.5 (Table 5), which is in the range of other previously reported polyimides (at $2 \mathrm{~atm}$ and $35^{\circ} \mathrm{C}$ ) $[4,14]$. On the other hand, functionalization with polar groups had significant impact on the diffusion coefficients - e.g., the $\mathrm{CH}_{4}$ diffusion coefficients followed the order: 6FDA-TrMSA $\left(0.09 \times 10^{-8} \mathrm{~cm}^{2} \mathrm{~s}^{-1}\right)<$ 6FDA-TrMCA $\left(0.66 \times 10^{-8} \mathrm{~cm}^{2} \mathrm{~s}^{-1}\right)<6$ FDA-TrMPD $\left(4.2 \times 10^{-8} \mathrm{~cm}^{2} \mathrm{~s}^{-1}\right)$. This effect was less pronounced for $\mathrm{CO}_{2}$ (Table 4); therefore, the high $\mathrm{CO}_{2} / \mathrm{CH}_{4}$ pure-gas permselectivity of 61 for 6FDA-TrMSA resulted primarily from its high $\mathrm{CO}_{2} / \mathrm{CH}_{4}$ diffusion selectivity. For comparison, 6FDA-TrMSA, 6FDA-TrMCA, and 6FDA-TrMPD displayed $\mathrm{CO}_{2} / \mathrm{CH}_{4}$ diffusion selectivity values of 17.2, 10 and 6.1, respectively (Table 5).

The gas permeability and selectivity of TEA-tSPI, the triethylamine sulfonate salt form of 6FDA-TrMSA (Scheme 1), along with other sulfonated polyimides were recently reported by Zhang et al. [48]. The TEA- $t$ SPI polyimide showed a higher $\mathrm{CO}_{2}$ permeability (52 vs. 19 Barrer) but lower $\mathrm{CO}_{2} / \mathrm{CH}_{4}$ selectivity (33 vs 61 ) than the 6FDA-TrMSA polyimide (Table 3). Interestingly, 6FDA-TrMSA and TEA-tSPI displayed similar $\mathrm{H}_{2}$ permeability 56-58 Barrer; however, 6FDA-TrMSA demonstrated high $\mathrm{H}_{2} / \mathrm{CH}_{4}$ selectivity of 180 , whereas TEA-tSPI displayed only a moderate selectivity of 37 [48]. This result may be attributed to less pronounced 
hydrogen bonding after replacing $-\mathrm{SO}_{3} \mathrm{H}$ by the bulkier and less polar $-\mathrm{SO}_{3} \mathrm{NH}\left(\mathrm{CH}_{2} \mathrm{CH}_{3}\right)_{3}$ group in the TEA-tSPI polyimide.

In comparison with a relevant commercial membrane material (e.g., cellulose triacetate), 6FDA-TrMSA exhibited a notably improved performance for all gas pairs (Table 3). The 6FDATMSA polyimide exhibited about two-fold higher $\mathrm{CO}_{2}$ permeability (19 vs. 6.6 Barrer) and $\sim 85 \%$ higher $\mathrm{CO}_{2} / \mathrm{CH}_{4}$ selectivity (61 vs. 33) than cellulose triacetate [50].

Finally, we briefly discuss the aging behavior of 6FDA-TrMSA. Physical properties and separation performance of low-free-volume polyimides are de-facto only mildy affected by the extremely slow densification of the polymer matrix — i.e., physical aging. This behavior was also confirmed for our $-\mathrm{SO}_{3} \mathrm{H}$-functionalized polyimide. In fact, a second sample of 6FDA-TrMSA (heat treated at $120{ }^{\circ} \mathrm{C}$ for $24 \mathrm{~h}$ followed by $200{ }^{\circ} \mathrm{C}$ for $2 \mathrm{~h}$ under vacuum) was tested after 3 months and displayed both $\mathrm{CO}_{2}$ permeability and $\mathrm{CO}_{2} / \mathrm{CH}_{4}$ permeability selectivities adherent to values obtained for the fresh sample.

\section{Table 4}

Diffusion coefficients and solubility coefficients of $\mathrm{CO}_{2}$ and $\mathrm{CH}_{4}$ for 6 FDA-TrMSA (2 atm and $\left.35^{\circ} \mathrm{C}\right)$.

\begin{tabular}{ccccc}
\hline Polymer & $\begin{array}{c}\text { Diffusion coefficient } \\
\end{array}$ & \multicolumn{2}{c}{$\left(10^{-8} \mathrm{~cm}^{2} \mathrm{~s}^{-1}\right)$} & \multicolumn{2}{c}{$\begin{array}{c}\text { Solubility coefficient } \\
\end{array}$} & $\left(10^{-2} \mathrm{~cm}^{3}(\mathrm{STP}) \mathrm{cm}^{-3} \mathrm{cmHg}^{-1}\right)$ \\
\hline & $\mathrm{CO}_{2}$ & $\mathrm{CH}_{4}$ & $\mathrm{CO}_{2}$ & $\mathrm{CH}_{4}$ \\
\hline 6FDA-TrMSA [this study] & 1.55 & 0.09 & 12.3 & 3.45 \\
6FDA-TrMCA [33] & 6.8 & 0.66 & 16 & 3.6 \\
6FDA-TrMPD [33] & 25 & 4.2 & 15 & 4.2 \\
\hline
\end{tabular}

${ }^{a}$ Determined from $D=P / S .{ }^{b}$ Measured by gravimetric sorption at $35^{\circ} \mathrm{C}$ and $2 \mathrm{~atm}$. 


\section{Table 5}

$\mathrm{CO}_{2} / \mathrm{CH}_{4}$ diffusion selectivity and solubility selectivity for $6 \mathrm{FDA}-\operatorname{TrMSA}\left(2 \mathrm{~atm}\right.$ and $\left.35^{\circ} \mathrm{C}\right)$.

Diffusion selectivity

Polymer

\begin{tabular}{ccc}
\hline & $\mathrm{CO}_{2} / \mathrm{CH}_{4}$ & $\mathrm{CO}_{2} / \mathrm{CH}_{4}$ \\
\hline 6FDA-TrMSA [this study] & 17.2 & 3.6 \\
6FDA-TrMCA [33] & 10 & 4.5 \\
6FDA-TrMPD [33] & 6.1 & 3.6 \\
\hline
\end{tabular}

Solubility selectivity

$(\alpha)_{S}$

\subsection{High-pressure pure- and mixed-gas transport properties}

In a first set of experiments, we determined the $\mathrm{CO}_{2}$ and $\mathrm{CH}_{4}$ permeability in pure-gas measurements up to 18 atm. As observed for other glassy polymers, the $\mathrm{CO}_{2}$ and $\mathrm{CH}_{4}$ permeability decreased with increasing pressure due to competitive sorption effects [52,53]. The $\mathrm{CO}_{2}$ permeability dropped from 18 to 14.5 Barrer, while $\mathrm{CH}_{4}$ permeability declined from 0.287 to 0.190 Barrer over a feed pressure range of 2 to $18 \mathrm{~atm}$ (Fig. 7a). Based on pure gas testing, the $\mathrm{CO}_{2} / \mathrm{CH}_{4}$ selectivity was $\sim 60$ at 2 atm but increased to a stable value of $\sim 80$ up to 18 atm (Fig. $7 \mathbf{b})$.

In a second series of experiments, the gas permeation properties of 6FDA-TrMSA were evaluated with a $1: 1 \mathrm{CO}_{2} / \mathrm{CH}_{4}$ mixture at $35^{\circ} \mathrm{C}$ and up to $36 \mathrm{~atm}$ feed pressure. Recent studies on $\mathrm{CO}_{2} / \mathrm{CH}_{4}$ mixed-gas sorption in glassy polyimides and cellulose triacetate demonstrated higher $\mathrm{CO}_{2} / \mathrm{CH}_{4}$ solubility selectivities in mixtures than obtained with pure gases obtained at the same partial gas pressure [54-56]. This positive effect on mixed-gas permeability selectivity due to competitive sorption effects is unfortunately overcome in most glassy polymers by a highly undesirable drop in mixed-gas diffusion selectivity, which leads to a net drop in $\mathrm{CO}_{2} / \mathrm{CH}_{4}$ permselectivity [54,56]. In rare cases, however, higher mixed-gas than pure-gas $\mathrm{CO}_{2} / \mathrm{CH}_{4}$ permeability selectivities have been reported where the positive effect of enhanced mixed-gas solubility selectivity dominated over the reduced mixed-gas diffusion selectivity [21,23,55,57]. 
In this study, the $\mathrm{CO}_{2}$ permeability of 6FDA-TrMSA dropped when tested under gas mixture conditions (Fig. 7a); furthermore, the sulfonated polyimide exhibited lower mixed-gas $\mathrm{CO}_{2} / \mathrm{CH}_{4}$ selectivity than obtained for pure gases at the same partial pressures (Fig. 7b). This drop in mixedgas selectivity was clearly evident by a continuous decrease in mixed-gas $\mathrm{CO}_{2}$ and an increase in $\mathrm{CH}_{4}$ permeability with increasing feed pressure (Fig. 7a). The enhanced $\mathrm{CH}_{4}$ mixed-gas permeability was an indication of $\mathrm{CO}_{2}$-induced plasticization; consequently, the $\mathrm{CO}_{2} / \mathrm{CH}_{4}$ mixedgas permeability selectivity dropped significantly from $\sim 60$ to $\sim 38$ by increasing the partial $\mathrm{CO}_{2}$ pressure from 2 to $18 \mathrm{~atm}$. Hence, although the $-\mathrm{SO}_{3} \mathrm{H}$ functionalization tightened the polyimide matrix by hydrogen bonding and improved the diffusion selectivity of the 6FDA-TrMSA polyimide under ideal pure-gas conditions, it could not prevent the $\mathrm{CO}_{2}$-induced polymer plasticization.

(a)

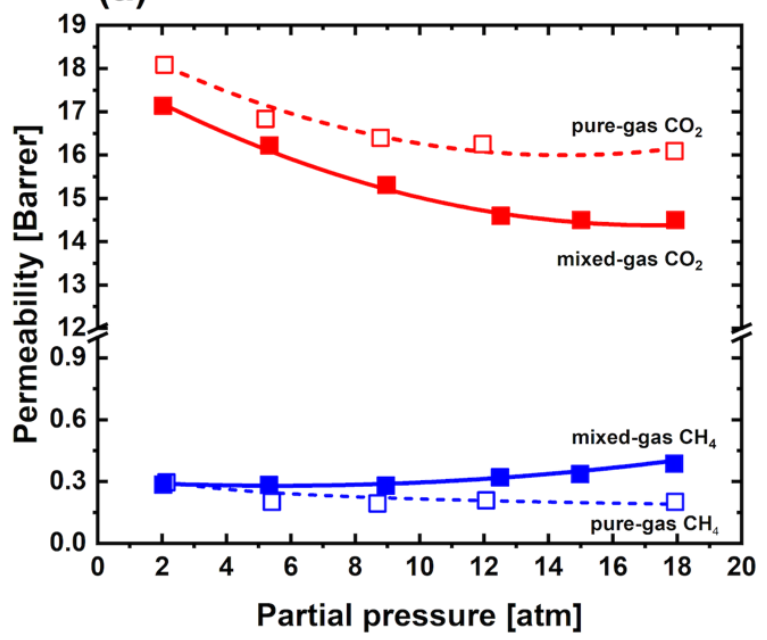

(b)

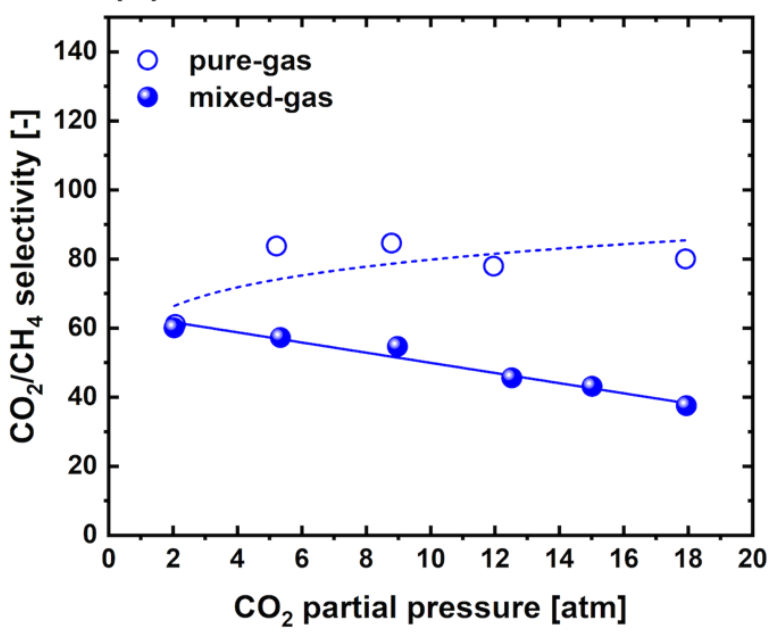

Fig. 7. (a) $\mathrm{CO}_{2}$ and $\mathrm{CH}_{4}$ pure- and mixed-gas permeability $v$ s. gas partial pressure of $6 \mathrm{FDA}-\mathrm{TrMSA}$ at $35^{\circ} \mathrm{C}$. (b) Pure- and mixed-gas $\mathrm{CO}_{2} / \mathrm{CH}_{4}$ selectivity of $6 \mathrm{FDA}-\mathrm{TrMSA} v$ s. $\mathrm{CO}_{2}$ partial pressure.

From a mixed-gas performance perspective, at $\sim 20 \mathrm{~atm}$ total pressure, 6FDA-TrMSA showed an equimolar $\mathrm{CO}_{2} / \mathrm{CH}_{4}$ mixed-gas selectivity of 55 , which was $\sim$ twofold higher than that of cellulose triacetate, the state-of-the-art polymer used for membrane-based natural gas sweetening 
[58], and 1.4 times that of the carboxyl-functionalized polyimide counterpart. However, the $\mathrm{COOH}$-functionalized polyimide (6FDA-TrMCA) presented a superior combination of permeability vs. permselectivity, with performance located closer to the 2008 pure- [59] and 2018 mixed-gas [11] trade-off curves than 6FDA-TrMSA, as shown in Fig. 8.

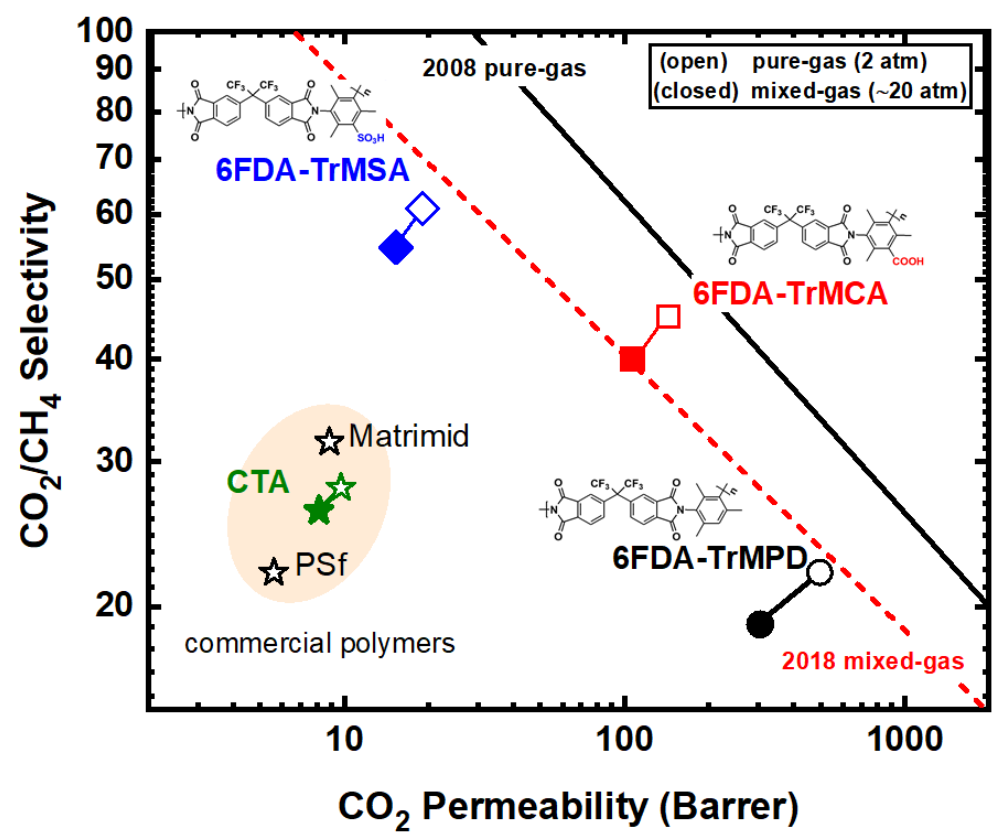

Fig. 8. Pure- (at $2 \mathrm{~atm}$ - open symbols) and mixed-gas ( $\sim 10$ atm partial $\mathrm{CO}_{2}$ pressure - closed symbols) $\mathrm{CO}_{2} / \mathrm{CH}_{4}$ selectivity vs. $\mathrm{CO}_{2}$ permeability of $6 \mathrm{FDA}-\mathrm{TrMSA}$ at $35{ }^{\circ} \mathrm{C}$ relative to 2008 pure- [59] and 2018 mixed-gas $\mathrm{CO}_{2} / \mathrm{CH}_{4}$ upper bounds (valid for $\sim 10 \mathrm{~atm}$ partial $\mathrm{CO}_{2}$ pressure at $35^{\circ} \mathrm{C}$ ) [11]. Mixed-gas performance of a commercial membrane polymer (e.g., cellulose triacetate [58]) is included for comparison.

\section{Conclusions}

A sulfonic-acid-functionalized polyimide was synthesized by a high-temperature one-step polycondensation reaction of 6FDA and TrMSA. The 6FDA-TrMSA polyimide properties were compared to the carboxylic acid- (6FDA-TrMCA) and the non-functionalized (6FDA-TrMPD) analogue polyimides. Incorporation of the highly polar $-\mathrm{SO}_{3} \mathrm{H}$ group promoted charge transfer 
complex formation and increased hydrogen bonding interactions, which led to significantly tighter chain packing (as demonstrated by lower BET surface area and fractional free volume), smaller chain $d$-spacing, and enhanced ideal gas-pair selectivity with undesirable decrease in gas permeability. The $-\mathrm{SO}_{3} \mathrm{H}$-substituted 6FDA-TrMSA polyimide presented a notable pure-gas $\mathrm{CO}_{2}$ diffusion selectivity of 17.2 at 2 atm and $35{ }^{\circ} \mathrm{C}$. 6FDA-TrMSA suffered from $\mathrm{CO}_{2}$-induced plasticization under mixed-gas conditions, as evidenced by enhanced $\mathrm{CH}_{4}$ permeability and continuous loss in $\mathrm{CO}_{2} / \mathrm{CH}_{4}$ selectivity with increased feed pressure. However, at $\sim 20$ atm total pressure, it still maintained an excellent mixed-gas $\mathrm{CO}_{2} / \mathrm{CH}_{4}$ selectivity of 55 , which is twofold higher than that of cellulose triacetate, which is the state-of-the-art membrane material used for industrial natural gas separation.

\section{Declaration of competing interest}

The authors declare no competing financial interests.

\section{CRediT authorship contribution statement}

Mahmoud A. Abdulhamid: Conceptualization, Methodology, Validation, Formal analysis, Investigation, Data curation, Writing - original draft, Visualization. Giuseppe Genduso: Methodology, Data curation, Visualization, Writing - review \& editing. Xiaohua Ma: Data curation. Ingo Pinnau: Conceptualization, Resources, Methodology, Writing - review \& editing, Visualization, Supervision, Funding acquisition, Project administration.

\section{Acknowledgments}

This work was supported by funding from King Abdullah University of Science and Technology (BAS/1/1323-01-01).

\section{Appendix A. Supplementary data}

Supplementary data to this article can be found at https://doi. org/10.1016/---. 


\section{References}

[1] D.-J. Liaw, K.-L. Wang, Y.-C. Huang, K.-R. Lee, J.-Y. Lai, C.-S. Ha. Advanced polyimide materials: syntheses, physical properties and applications. Prog. Polym. Sci. 37 (2012) 907-974.

[2] H.H. Hoehn, J.W. Richter, Aromatic polyimide, polyester and polyamide separation membranes. US Patent 3,899,309 (1975).

[3] T.H. Kim, W.J. Koros, G.R. Husk, K.C. O’Brien, Relationship between gas separation properties and chemical structure in a series of aromatic polyimides. J. Membr. Sci. 37 (1988) 45-62.

[4] K. Tanaka, H. Kita, M. Okano, K.-I. Okamoto, Permeability and permselectivity of gases in fluorinated and non-fluorinated polyimides, Polymer 33 (1992) 585-592.

[5] S.A. Stern, Polymers for gas separations: the next decade. J. Membr. Sci. 94 (1994) 1-65.

[6] Y. Hirayama, T. Yoshinaga, Y. Kusuki, K. Ninomiya, T. Sakakibara, T. Tamari. Relation of gas permeability with structure of aromatic polyimides I. J. Membr. Sci. 111 (1996) 169-182.

[7] Y. Xiao, B.T. Low, S.S. Hosseini, T.S. Chung, D.R. Paul, The strategies of molecular architecture and modification of polyimide-based membranes for $\mathrm{CO}_{2}$ removal from natural gas-A review, Progr. Polym. Sci. 34 (2009) 561-580.

[8] B.S. Ghanem, N.B. McKeown, P.M. Budd, N.M. Al-Harbi, D. Fritsch, K. Heinrich, L. Starannikova, A. Tokarev, Y. Yampolskii, Synthesis, characterization, and gas permeation properties of a novel group of polymers with intrinsic microporosity: PIM-polyimides, Macromolecules 42 (2009) 7881-7888.

[9] C. Álvarez, A.E. Lozano, J.G. de la Campa, High-productivity gas separation membranes derived from pyromellitic dianhydride and nonlinear diamines, J. Membr. Sci. 501 (2016) 191-198.

[10] A. Tena, S. Shishatskiy, D. Meis, J. Wind, V. Filiz, V. Abetz, Influence of the composition and imidization route on the chain packing and gas separation properties of fluorinated copolyimides, Macromolecules 50 (2017) 5839-5849.

[11] Y. Wang, X. Ma, B.S. Ghanem, F. Alghunaimi, I. Pinnau, Y. Han. Polymers of intrinsic microporosity for energy-intensive membrane-based gas separations. Mater. Today Nano 3 (2018) 69-95.

[12] H. Sanaeepur, A.E. Amooghin, S. Bandehali, A. Moghadassi, T. Matsuura, B. Van der Bruggen, Polyimides in membrane gas separation: monomer's molecular design and structural engineering, Progr. Polym. Sci. 91 (2019) 80-125 
[13] T. Corrado, R. Guo, Macromolecular design strategies toward tailoring free volume in glassy polymers for high performance gas separation membranes, Mol. Syst. Des. Eng. 5 (2020) 22-48.

[14] K. Tanaka, M. Okano, H. Toshino, H. Kita, K.-I. Okamoto. Effect of methyl substituents on permeability and permselectivity of gases in polyimides prepared from methylsubstituted phenylenediamines. J. Polym. Sci., Part B: Polym. Phys. 30 (1992) 907-914.

[15] S.X. Cheng, T.S. Chung, R. Wang, R.H. Vora, Gas-sorption properties of 6FDAdurene/1,4-phenylenediamine (pPDA) and 6FDA-durene/1,3- phenylenediamine (mPDA) copolyimides, J. Appl. Polym. Sci. 90 (2003) 2187-2193.

[16] W.H. Lin, R.H. Vora, T.S. Chung, Gas transport properties of 6FDA-durene/1,4phenylenediamine (pPDA) copolyimides, J. Polym Sci Part B: Polym. Phys. 38 (2000) 2703-2713.

[17] W. Qiu, L. Xu, C.-C. Chen, D.R. Paul, W.J. Koros, Gas separation performance of 6FDAbased polyimides with different chemical structures, Polymer 54 (2013) 6226-6235.

[18] S.A. Stern, H. Kawakami, A.Y. Houde, G. Zhou, Material and process for separating carbon dioxide from methane, U.S. Patent 5,591,250 (1997).

[19] C.H. Jung, Y.M. Lee, Gas permeation properties of hydroxyl-group containing polyimide membranes, Macromol. Res. 16 (2008) 555-560.

[20] X. Ma, R. Swaidan, Y. Belmabkhout, Y.H. Zhu, E. Litwiller, M. Jouiad, I. Pinnau, Y. Han, Synthesis and gas transport properties of hydroxyl-functionalized polyimides with intrinsic microporosity, Macromolecules 45 (2012) 3841-3849.

[21] R. Swaidan, B. Ghanem, E. Litwiller, I. Pinnau. Effects of hydroxyl-functionalization and thermal annealing on high pressure pure- and mixed-gas $\mathrm{CO}_{2} / \mathrm{CH}_{4}$ separation by polyimide membranes based on 6FDA and triptycene-containing dianhydrides. J. Membr. Sci. 475 (2015) 571-581.

[22] S. Yi, X. Ma, I. Pinnau, W.J. Koros, A high-performance hydroxyl-functionalized polymer of intrinsic microporosity for an environmentally attractive membrane-based approach to decontamination of sour natural gas. J. Mater. Chem. A 2015, 3, 22794- 22806.

[23] K.L. Gleason, Z.P. Smith, Q. Liu, D.R. Paul, B.D. Freeman, Pure- and mixed-gas permeation of $\mathrm{CO}_{2}$ and $\mathrm{CH}_{4}$ in thermally rearranged polymers based on 3,3'-dihydroxy4,4'-diamino-biphenyl (HAB) and 2,2'-bis-(3,4-dicarboxyphenyl) hexafluoropropane dianhydride (6FDA), J. Membr. Sci. 475 (2015) 204-214.

[24] R. Swaidan, B. Ghanem, E. Litwiller, I. Pinnau, Effects of hydroxyl-functionalization and sub-Tg thermal annealing on high pressure pure-and mixed-gas $\mathrm{CO}_{2} / \mathrm{CH}_{4}$ separation by polyimide membranes based on 6FDA and triptycene-containing dianhydrides, J. Membr. Sci. 475 (2015) 571-581. 
[25] N. Alaslai, B. Ghanem, F. Alghunaimi, E. Litwiller, I. Pinnau, Pure-and mixed- gas permeation properties of highly selective and plasticization resistant hydroxyl-diaminebased 6FDA polyimides for $\mathrm{CO}_{2} / \mathrm{CH}_{4}$ separation, J. Membr. Sci. 505 (2016) 100-107.

[26] X. Ma, M. Abdulhamid, X. Miao, I. Pinnau, Facile synthesis of a hydroxyl-functionalized Tröger's base diamine: a new building block for high-performance polyimide gas separation membranes, Macromolecules 50 (2017) 9569-9576.

[27] N. Alaslai, X. Ma, B. Ghanem, Y. Wang, F. Alghunaimi, I. Pinnau, Synthesis and characterization of a novel microporous dihydroxyl-functionalized triptycene-diaminebased polyimide for natural gas membrane separation. Macromol. Rapid Commun. 2017, $38,1700303$.

[28] S.-H. Park, K.-J. Kim, W.-W. So, S.-J. Moon, S.-B. Lee, Gas separation properties of 6FDA-based polyimide membranes with a polar group, Macromol. Res.11, (2003) 157162.

[29] J.D. Wind, D.R. Paul, W.J. Koros, Natural gas permeation in polyimide membranes, J. Membr. Sci. 228 (2004) 227-236.

[30] A.M. Kratochvil, W.J. Koros. Decarboxylation-induced cross-linking of a polyimide for enhanced $\mathrm{CO}_{2}$ plasticization resistance. Macromolecules 41(2008) 7920-7927.

[31] W. Qiu, C.-C. Chen, L. Xu, L. Cui, D.R. Paul, W.J. Koros. Sub-Tg cross-linking of a polyimide membrane for enhanced $\mathrm{CO}_{2}$ plasticization resistance for natural gas separation. Macromolecules 44 (2011) 6046-6056.

[32] X. Ma, M. Mukaddam, I. Pinnau, Bifunctionalized intrinsically microporous polyimides with simultaneously enhanced gas permeability and selectivity, Macromol. Rapid Commun. 37 (2016) 900-904.

[33] M.A. Abdulhamid, G. Genduso, Y. Wang, X. Ma, I. Pinnau. Plasticization-resistant carboxyl-functionalized 6FDA-polyimide of intrinsic microporosity (PIM-PI) for membrane-based gas separation. Ind. Eng. Chem. Res. 59 (2020) 5247-5256.

[34] R. Thür, V. Lemmens, D. Van Havere, M. van Essen, K. Nijmeijer, I.F.J. Vankelecom, Tuning 6FDA-DABA membrane performance for $\mathrm{CO}_{2}$ removal by physical densification and decarboxylation cross-linking during simple thermal treatment, J. Membr. Sci. 610 (2020) 118195.

[35] E. Vallejo, G. Pourcelly, C. Gavach, R. Mercier, M. Pineri. Sulfonated polyimides as proton conductor exchange membranes. Physicochemical properties and separation $\mathrm{H}^{+} / \mathrm{M}^{\mathrm{z}}$ by electrodialysis comparison with a perfluorosulfonic membrane. J. Membr. Sci. 160 (1999) 127-137.

[36] N. Cornet, O. Diat, G. Gebel, F. Jousse, D. Marsacq, R. Mercier, M. Pineri. Sulfonated polyimide membranes: a new type of ion-conducting membrane for electrochemical applications. J. New Mat. Electrochem. Systems 3 (2000) 33-42. 
[37] T. Watari, J. Fang, K. Tanaka, H. Kita, K. Okamoto, T. Hirano. Synthesis, water stability and proton conductivity of novel sulfonated polyimides from 4,4'-bis(4aminophenoxy)biphenyl-3,3'-disulfonic acid. J. Membr. Sci. 230 (2004) 111-120.

[38] X. Ye, H. Bai, W.S.W. Ho. Synthesis and characterization of new sulfonated polyimides as proton-exchange membranes for fuel cells. J. Membr. Sci. 279 (2006) 570-577.

[39] C. Liu, L. Li, Z. Liu, M. Guo, L. Jing, Liu, Z. Jiang, T. Matsumoto, M.D. Guiver. Sulfonated naphthalenic polyimides containing ether and ketone linkages as polymer electrolyte membranes. J. Membr. Sci. 366 (2011) 73-81.

[40] X. Guo, J. Fang, T. Watari, K. Tanaka, H. Kita, K. Okamoto. Novel sulfonated polyimides as polyelectrolytes for fuel cell application. 2. Synthesis and proton conductivity of polyimides from 9,9-bis(4-aminophenyl)fluorene-2,7-disulfonic acid. Macromolecules, 35 (2002) 6707-6713.

[41] W. Zhou, T. Watari, H. Kita, K. Okamoto, Gas permeation properties of flexible pyrolytic membranes from sulfonated polyimides. Chem. Lett. (2002) 534. SO3H

[42] F. Piroux, E. Espuche, R. Mercier, M. Pinéri, G. Gebel. Gas transport mechanism in sulfonated polyimides consequences on gas selectivity. J. Membr. Sci. 209 (2002) 241253. $\mathrm{SO} 3 \mathrm{H}$

[43] Y.K. Kim, H.B. Park, Y.M. Lee. Carbon molecular sieve membranes derived from metalsubstituted sulfonated polyimide and their gas separation properties. J. Membr. Sci. 226 (2003) 145-158.

[44] F. Piroux, E. Espuche, R. Mercier. The effects of humidity on gas transport properties of sulfonated copolyimides. J. Membr. Sci. 232 (2004) 115-122. SO3H

[45] Md. Nurul Islam, W. Zhou, T. Honda, K. Tanaka, H. Kita, K.-I. Okamoto, Preparation and gas separation performance of flexible pyrolytic membranes by low-temperature pyrolysis of sulfonated polyimides. J. Membr. Sci. 261 (2005) 17-263. SO3H

[46] K. Tanaka, Md. Nurul Islam, M. Kido, H. Kita, K.-I. Okamoto. Gas permeation and separation properties of sulfonated polyimide membranes. Polymer 47 (2006) 4370-4377. $\mathrm{SO} 3 \mathrm{H}$

[47] H.S. Im, B.S. Lee, B.S. Lee, S.W. Yoon, H.C. Koh, C.S. Lee, S.Y. Ha, S.I. Cheong, J.W. Rhim, Gas permeation properties of sulfonated 6FDA-based polyimide membranes exchanged with metal ions. Polymer (Korea) 33 (2009) 555-560.

[48] D. Zhang, J. G. Seong, W. H. Lee, S. Ando, Y. Wan, Y.M. Lee, Y. Zhuang. Effects of sulfonate incorporation and structural isomerism on physical and gas transport properties of soluble sulfonated polyimides. Polymer 191 (2020) 122263.

[49] M. Hasegawa, I. Mita, M. Kochi, R. Yokota. Charge-transfer emission spectra of aromatic polyimides. J. Polym. Sci., Part C: Polym. Lett. 27 (1989) 263-269 
[50] A.C. Puleo, D. R. Paul, S. S. Kelley. The effect of degree of acetylation on gas sorption and transport behavior in cellulose acetate. J. Membr. Sci. 47 (1989) 301-332.

[51] D.F. Sanders, Z.P. Smith, R. Guo, L.M. Robeson, J.E. McGrath, D.R. Paul, B.D. Freeman, Energy-efficient polymeric gas separation membranes for a sustainable future: A review, Polymer 54 (2013) 4729-4761.

[52] D.R. Paul, Gas sorption and transport in glassy polymers, Ber. Bunsenges. Phys. Chem. 83 (1979) 294-302.

[53] W.J. Koros, A.H. Chan, D.R. Paul, Sorption and transport of various gases in polycarbonate, J. Membr. Sci. 2 (1977) 165-190.

[54] G. Genduso, B.S. Ghanem, I. Pinnau. Experimental mixed-gas permeability, sorption and diffusion of $\mathrm{CO}_{2}-\mathrm{CH}_{4}$ mixtures in $6 \mathrm{FDA}-m$ PDA polyimide membrane: Unveiling the effect of competitive sorption on permeability selectivity. Membranes 9 (2019) 10.

[55] E. Ricci, F.M. Benedetti, M.E. Dose, M.G. De Angelis, B.D. Freeman, D.R. Paul, Competitive sorption in $\mathrm{CO}_{2} / \mathrm{CH}_{4}$ separations: the case of $\mathrm{HAB}-6 \mathrm{FDA}$ polyimide and its TR derivative and a general analysis of its impact on the selectivity of glassy polymers at multicomponent conditions, J. Membr. Sci. 612 (2020) 118374.

[56] G. Genduso, I. Pinnau. Quantification of sorption, diffusion, and plasticization properties of cellulose triacetate films under mixed-gas $\mathrm{CO}_{2} / \mathrm{CH}_{4}$ environment. J. Membr. Sci. 610 (2020) 118269.

[57] F. Alghunaimi, B. Ghanem, N. Alaslai, M. Mukaddam, I. Pinnau, Triptycene dimethylbridgehead dianhydride-based intrinsically microporous hydroxyl-functionalized polyimide for natural gas upgrading, J. Membr. Sci. 520 (2016) 240-246.

[58] R. Swaidan, B. Ghanem, M. Al-Saeedi, E. Litwiller, I. Pinnau, Role of intrachain rigidity in the plasticization of intrinsically microporous triptycene-based polyimide membranes in mixed-gas $\mathrm{CO}_{2}-\mathrm{CH}_{4}$ separations, Macromolecules 47 (2014) 7453-7462.

[59] L. M. Robeson, The upper bound revisited, J. Membr. Sci. 320 (2008) 390-400. 